\title{
Autoritarismo e resistência indígena no Brasil
}

\section{Authoritarianism and the indigenous resistance in Brazil}

\section{Autoritarismo y resistencia indígena en Brasil}

\author{
Luiz Henrique Eloy Amado ${ }^{1, a}$ \\ adv.luizeloy@gmail.com | https://orcid.org/0000-0001-9073-6086 \\ ${ }^{1}$ Articulação dos Povos Indígenas do Brasil. Brasília, DF, Brasil. \\ a Doutorado em Antropologia Social pela Universidade Federal do Rio de Janeiro.
}

\section{Resumo}

Esta nota resulta de reflexões iniciais sobre a atual conjuntura brasileira no que tange aos desafios postos aos povos indígenas, diante de um governo declaradamente anti-indígena. Considerando a perspectiva histórica da política indigenista brasileira, observam-se elementos que nos instigam a analisar a relação do Estado com os povos originários e a capacidade que o movimento indígena brasileiro tem de articulação visando à resistência. São necessários saberes e práticas que exigem, cada vez mais, o rompimento com o pensamento autoritário e colonialista tão presente no contexto brasileiro.

Palavras-chave: Movimento indígena; Povos indígenas; Resistência; Autoritarismo; Amazônia.

\begin{abstract}
This text is product of the initial attempts to think about the current Brazilian conjuncture regarding the challenges posed to indigenous peoples since they are confronted with a government who have declared to be anti-indigenous. From the historical perspective of Brazilian governmental policy towards indigenous, we observe elements that push us to analyze the relationship of the State with the indigenous peoples and the Brazilian indigenous movement' capacity for interacting to resist. Knowledge and practices that demand more and more a break with the authoritarian and colonialist thinking so present in the Brazilian context are indispensable.
\end{abstract}

Keywords: Indigenous movement; Indigenous peoples; Resistance; Authoritarianism; Amazonia. 


\section{Resumen}

Esta nota resulta de reflexiones iniciales a cerca de la coyuntura brasileña actual por lo que se refiere a los desafíos que los pueblos indígenas tienen que enfrentar frente a un Gobierno que expresa clara y determinadamente ser antiindígena. Observando la perspectiva histórica de la política indigenista brasileña, hay elementos que instigan el análisis de la relación del Estado con los pueblos indígenas y la capacidad que el movimiento indígena brasileño tiene de articularse para resistir. Son necesarios saberes y prácticas que exigen cada vez más el rompimiento con el pensamiento autoritario y colonialista tan presente en el contexto brasileño.

Palabras clave: Movimiento indígena; Pueblos indígenas; Resistencia; Autoritarismo; Amazonia.

Este artigo compõe o Dossiê Saúde, etnicidades e diversidade cultural: comunicação, territórios e resistências.

Contribuição dos autores: o autor é responsável por todo o texto.

Declaração de conflito de interesses: não há.

Fontes de financiamento: não houve.

Considerações éticas: não há.

Agradecimentos/Contribuições adicionais: não há.

Histórico do artigo: submetido: 11 out. 2019 | aceito: 11 out. 2019 | publicado: 20 dez. 2019.

Apresentação anterior: não houve.

Licença CC BY-NC atribuição não comercial. Com essa licença é permitido acessar, baixar (download), copiar, imprimir, compartilhar, reutilizar e distribuir os artigos, desde que para uso não comercial e com a citação da fonte, conferindo os devidos créditos de autoria e menção à Reciis. Nesses casos, nenhuma permissão é necessária por parte dos autores ou dos editores. 
O processo histórico do Brasil é composto de lutas e conflitos e marcado por uma cultura autoritária acionada de diversas formas para manter a 'ordem social'. A teoria política que fomentou esse modelo repressivo foi alimentada por grupos políticos, militares e até intelectuais por suas intervenções ideológicas, deixando impressas no Estado ações marcadas também pelo sangue indígena. Desde o início da implantação do projeto colonial neste território originalmente habitado apenas pelos povos indígenas, a máquina estatal foi se enraizando por meio de medidas extremamente violentas que culminaram para o extermínio de vários povos indígenas. Num primeiro momento, questionou-se se tais indivíduos tinham alma, o que só veio a ser reconhecido posteriormente por meio de uma bula papal ${ }^{1}$, elevando os indígenas à condição de seres humanos - "os índios são verdadeiramente homens"1- e, portanto, passíveis de evangelização. O que se entende hoje por Estado brasileiro foi constituído a partir de atitudes autoritárias que não levaram em consideração os territórios originários, a cultura, a organização social, os sistemas jurídicos próprios, as línguas e os modos próprios de ver e de entender o mundo da ótica indígena.

O campo da política indigenista no Brasil, desde o período colonial até os dias atuais, ou seja, sob o manto republicano, foi idealizado e implementado a partir da perspectiva da desterritorialização, dominação e assimilação dos povos originários. O sistema colonial, marcado principalmente pela implantação do processo de conquista, com o qual se buscou legitimar a escravização da mão de obra indígena, o processo ‘civilizatório' por meio da catequese e o apossamento do território; foi também um período marcado pela forte resistência indígena. Os povos indígenas, cada qual à sua maneira e estratégia, empreenderam uma resistência qualificadai, de modo que "novas sociedades e novos tipos de sociedade"2, surgiram nesse contexto de conquista colonial. Entretanto, o "conhecimento dessa realidade esteve viciado pelo olhar do cronista que desde o início naturalizava essas sociedades, dividindo-as em 'Tupis' e 'Tapuias' (aliados/inimigos)”, conforme apontam Pacheco de Oliveira e Freire ${ }^{3}$, favorecendo, assim, a consolidação do projeto colonial, que consistia na dominação e subjugação dos povos indígenas.

Temos acompanhado ao longo do tempo uma intensa mobilização política dos povos indígenas por meio de suas instituições representativas. São manifestações, em sua grande maioria, direcionadas ao Estado, sempre com a perspectiva de exigir o direito à vida dos povos originários deste país. Não à toa, o Estado tem desempenhado o papel de principal violador dos direitos humanos dos povos indígenas com a implementação de políticas que afetaram drasticamente os territórios e consequentemente a vida desses povos. 'Etnocídio' é termo derivado da terminologia genocídio utilizado para se referir à violência marcada notadamente pela conduta impositiva de uma cultura sobre a outra, valendo-se de uma suposta soberania racial. Neste sentido, o termo se aplica ao modo como o Estado brasileiro se relacionou e tem se relacionado com os povos indígenas. As táticas coloniais adotadas subjugaram os povos à dominação, à escravidão e ao extermínio. Por um lado, a ordem era integrar os 'índios' à chamada comunhão nacional, numa clara tentativa de 'branquear' todos, e assim perderem seu pertencimento étnico. Por outro, no nível mais local, os agentes estatais promoveram o desterro, ao efetuar remoções forçadas das terras tradicionais e/ou produzindo documentos legais, com o nítido objetivo de oferecer segurança jurídica aos coronéis e fazendeiros locais que se apoderaram de extensos pedaços de terras públicas nas mais diversas regiões do Brasil profundo.

$\mathrm{Na}$ atual conjuntura, vemos claramente como o governo do presidente Bolsonaro se relaciona com os povos indígenas de maneira autoritária e colonial. A Constituição Federal brasileira completou 30 anos em outubro de 2018 e, pela primeira vez no período pós-redemocratização, temos um presidente declaradamente anti-indígena, que prolifera um discurso de não demarcar as terras indígenas (TI) tradicionalmente ocupadas, e desloca a pauta socioambiental para um discurso de ideário moralista, negando o importante papel que a Amazônia brasileira e os territórios indígenas cumprem no equilíbrio climático e bem-estar da

"O contato dos povos indígenas com os invasores coloniais - portugueses, franceses, holandeses etc. - não pode ser reduzido ao binômio extermínio e mestiçagem. Desde as primeiras relações de escambo ${ }^{4}$, passando pelas inúmeras alianças guerreiras até o desespero causado pelas epidemias de varíola, cada povo indígena reagiu a todos os contatos a partir do seu próprio dinamismo e criatividade"2. 
humanidade. As medidas adotadas nos primeiros meses de governo foram decisões que não levaram em consideração a autodeterminação, o respeito ao direito cultural e o princípio da dignidade sociocultural dos povos. A Medida Provisória ${ }^{\circ} 870$ de 2019 , assinada na cerimônia de posse e posteriormente convertida na Lei ${ }^{0}$ 13.844, de junho de 2019, deslocou a competência da Fundação Nacional do Índio (Funai), para "identificar, demarcar e registrar" terras indígenas e o licenciamento ambiental nesses territórios, para o Ministério da Agricultura, Pecuária e Abastecimento, órgão controlado por representantes do agronegócio brasileiro e declaradamente contra o reconhecimento e proteção dos territórios tradicionais. O Brasil continua em mora com os povos indígenas, pois ainda há um número significativo de suas terras a serem demarcadas. Entretanto, o órgão indigenista oficial do Estado - a Funai - passa por uma situação aguda terminal, sistemicamente provocada. O Projeto de Lei Orçamentária para o ano de 2020 prevê para esse órgão um orçamento ínfimo, que passará dos atuais 600 milhões para 130 milhões 6 .

No início do segundo semestre de 2019, ganharam repercussão internacional os incêndios que assolaram a Amazônia, um símbolo concreto da política ambiental irresponsável. Segundo dados do Instituto Nacional de Pesquisas Espaciais (Inpe), entre 20 de julho e 20 de agosto, houve 33.060 focos de calor na Amazônia Legal no Brasil. "Nesse período, as dez terras indígenas mais afetadas pelos incêndios foram o Parque Indígena Araguaia (TO), a TI Pimentel Barbosa (MT), TI Parabubure (MT), TI Apyterewa (PA), TI Marãiwatsédé (MT), TI Kayapó (PA), TI Areões (MT), TI Kanela (MA), TI Mundurucu (PA) e a TI Pareci (MT)"”. Ao todo, ocorreram 3.553 focos de calor em 148 terras indígenas da Amazônia brasileira. As queimadas também atingiram os territórios habitados por grupos isolados. Além disso, grilagem, pecuária, garimpo e flexibilização da legislação provocaram o desmatamento de 39 mil hectares na bacia do Xingu entre maio e junho de 2019; isso equivale a 533 árvores derrubadas por minuto. Muitas terras indígenas, tais como a TI Vale do Javari, Alto Rio Guaná no Pará e o território do povo Tembé7, estão sendo invadidas por garimpeiros e madeireiros ilegais. Isto tem gerado muitos conflitos, pois na medida que o Estado brasileiro não protege estas áreas, os povos indígenas têm protegido seu território com a própria vida. Recentemente, a Escola Nacional de Saúde Pública Sergio Arouca (Ensp), da Fundação Oswaldo Cruz (Fiocruz) divulgou um estudo constatando a contaminação, pelo mercúrio, no povo Yanomami. O estudo revela a presença de mercúrio em $56 \%$ das mulheres e crianças da região de Maturacá. "O metal faz parte de um processo tradicional utilizado no garimpo para viabilizar a separação do ouro dos demais sedimentos". A TI Yanomami possui nove milhões de hectares, cerca de 27 mil pessoas, e mais de 300 aldeias distribuídas pelo território, e a comunidade denuncia a presença de 20 mil garimpeiros ilegais. "O mercúrio provoca alterações diretas no sistema nervoso central, causando problemas de ordem cognitiva e motora, perda de visão, doenças cardíacas entre outras debilidades”.

No Congresso brasileiro, a antiga bancada 'ruralista' mudou a nomenclatura para Frente Parlamentar da Agropecuária, e tem encabeçado temas como inviabilização da demarcação de terras indígenas e de comunidades quilombolas; liberação de agrotóxicos; liberação de porte de arma para produtor rural; flexibilização da legislação ambiental e do trabalho escravo; diminuição de áreas protegidas; liberação de mineração e arrendamento em terras indígenas, além de ser base aliada do governo Bolsonaro. Possui forte representação: "na Câmara, conta com 225 deputados filiados, representando 44\% do total de votos (513). No Senado, os ruralistas detêm 32 das 81 cadeiras disponíveis”.

São tempos pós-modernos nos quais o movimento indígena brasileiro se apropria de fórmulas e símbolos para fazer a resistência qualificada. Ainda assim, as táticas coloniais continuam sendo acionadas pelos representantes do Estado: a cooptação e a repressão. Com a pauta de mineração e agricultura em terras indígenas, o governo busca aqueles que estão desconectados de seus territórios para fazer coro ao seu discurso. Sob a alegação de implementar o 'progresso do índio', vale-se de uma visão etnocêntrica para incentivar cada vez mais os 'saques' aos territórios protegidos.

Os povos indígenas têm demonstrado uma profunda capacidade de resistência qualificada contra as violações dos seus direitos, cumprindo agendas em diversas instâncias políticas pelo mundo, com único 
intuito de continuar a fazê-la para garantirem a sua existência enquanto povos culturalmente diferenciados. Esta capacidade política os povos indígenas têm a oferecer para toda a sociedade envolvente.

\section{Referências}

1. Paulo III [Papa]. Sublimus Deus [bula promulgada]. Roma; 1537.

2. Monteiro JM. Os negros da terra: índios e bandeirantes nas origens de São Paulo. 2. ed. São Paulo: Companhia das Letras; 1995. p. 55.

3. Oliveira JP, Freire CAR. A presença indígena na formação do Brasil. Brasília, Rio de Janeiro: MEC, Secad, Laced; Museu Nacional; 2006. p. 51.

4. Marchant A. Do escambo à escravidão: as relações econômicas de portugueses e índios na colonização do Brasil. São Paulo: Editora Nacional; 1980.

5. Presidência da República (BR), Secretaria Geral. Lei no 13.844 de 18 de junho de 2019. Estabelece a organização básica dos órgãos da Presidência da República e dos Ministérios; altera as Leis nos 13.334, de 13 de setembro de 2016, 9.069, de 29 de junho de 1995, 11.457, de 16 de março de 2007, 9.984, de 17 de julho de 2000, 9.433, de 8 de janeiro de 1997, 8.001, de 13 de março de 1990, 11.952, de 25 de junho de 2009, 10.559, de 13 de novembro de 2002, 11.440, de 29 de dezembro de 2006, 9.613, de 3 de março de 1998,11.473, de 10 de maio de 2007, e 13.346, de 10 de outubro de 2016; e revoga dispositivos das Leis nos 10.233, de 5 de junho de 2001, e 11.284, de 2 de março de 2006, e a Lei no 13.502, de $1^{\circ}$ de novembro de 2017. DOU [Internet]. 2019 jun. 18 [citado em 2019 nov. 05]. Disponível em http://www.planalto.gov.br/ccivil 03/ Ato2019-2022/2019/Lei/L13844.htm.

6. Câmara dos Deputados (BR). Lei Orçamentária Anual (LOA 2020): Projeto de Lei no. 22/2019-CN. 2019 [citado em 2019 nov. 05]. Disponível em https://www2.camara.leg.br/orcamento-da-uniao/leisorcamentarias/loa/2020/tramitacao/proposta-do-poder-executivo.

7. Roman C. ISA mostra Terras Indígenas mais afetadas por incêndios na Amazônia brasileira. Instituto Socioambiental [Internet]; Brasília, DF: Instituto Socioambiental; 2019 [acesso em 23 ago. 2019]. [cerca de 5 telas]. Disponível em: https://www.socioambiental.org/pt-br/noticias-socioambientais/isa-mostraterras-indigenas-mais-afetadas-por-incendios-na-amazonia-brasileira.

8. Leonel F. Contaminação por mercúrio se alastra na população Yanomani. Informe ENSP [Internet]; 16 ago 2019 [citado em 2019 out. 22]. [cerca de 2 telas]. Disponível em: http://www.ensp.fiocruz.br/ portal-ensp/informe/site/materia/detalhe/46979.

9. Nova Frente Parlamentar da Agropecuária reúne 257 deputados e senadores; com 25, PSL de Bolsonaro só fica atrás de PP e PSD. De olho nos ruralistas [Internet]. Brasília, DF: Observatório de agronegócio no Brasil; 2019 [citado em 2019 out. 25]. [cerca de 7 telas]. Disponível em:https://deolhonosruralistas. com.br/2019/03/22/nova-frente-parlamentar-da-agropecuaria-reune-257-deputados-e-senadores-com25-psl-de-bolsonaro-so-fica-atras-de-pp-e-psd/. 